\title{
NO REINO DAS ÁGUAS: ENCANTADOS, NATUREZA E CULTURA DO PANTANAL
}

\author{
Mário Cezar Silva Leite
}

RESUMO: This article stemmed from oral accounts about the Chacorore Bay, collected in field researches, in the Pantanal mato-grossense-MT, in the region of Barão de Melgaço. Through the fluency of the voice, the memory of the Pantanal communities, and of the waters, a map is obtained that goes beyond the geographical lines, the data and the natural elements. Chacorore is an enchanted bay. The Chacororé waters, in the Pantanal dwellers' imaginary and popular culture, seem to belong and be two distinct universes at the same time. The intersectional shaping of the enchantment, between natural and supernatural, also reaches the beings and myths that live in the Chacororé. In many cases, the imaginary beings are noticed in this intersection and are given a physical materiality.

PALAVRAS-CHAVE: Pantanal, Narrativas Orais, Mitos, Imaginário.

Nos últimos anos muito se tem pesquisado e escrito sobre o Pantanal. Entretanto, o conjunto de trabalhos, pesquisas, dissertações e teses, em áreas diversas e com abordagens e enfoques muito variados, trata majoritariamente de questões e preocupações vinculadas ao meio ambiente, via de regra desvinculadas da população que o habita. Claro que esse conjunto tem contribuído em muito para a percepção e resolução de uma série de problemas que, numa medida ou outra, diz respeito a todos nós preocupados com o nível de contaminação das águas, a sobrevivência de espécies ameaçadas da fauna e da flora, as queimadas anuais, o ressecamento de lagoas e baías, a preservação do meio ambiente e ecossistemas, o comportamento da fauna ou da flora diante de novas condições ambientais etc. No todo, esses trabalhos ajudam-nos a entender e perceber como o sistema Pantanal tem se comportado e enfrentado suas próprias questões. Numa recente pesquisa ${ }^{1}$, da qual participei, do Ministério da Integração Nacional, realizada por pesquisadores da Universidade Federal de Mato Grosso (UFMT) e Universidade Federal de Mato Grosso do Sul (UFMS), cujo objetivo era o levantamento bibliográfico/e ou documental "de obras científicas, literárias e artísticas", "numa perspectiva histórico-antropológica" sobre o Pantanal, de 1960 a 2002, de vários eixos temáticos desdobrados das Ciências Humanas e Sociais e das Letras verificamos que em todos os gêneros (livros, artigos, teses, dissertações, relatórios etc) o conjunto a ser desconsiderado (centrado em aspectos que não consideravam a população ou suas relações com o meio) era significativamente (assustadoramente?) maior.

Doutor em Comunicação e Semiótica pela PUC-SP, professor de literatura brasileira no Departamento de Letras e do Mestrado em Estudos de Linguagem/Universidade Federal de Mato Grosso (UFMT).

${ }^{1}$ O Projeto Memória do Homem Pantaneiro, conveniado entre o MI/IICA/FAPEC, foi coordenado em Mato Grosso por Lylia da Silva Guedes Galetti (UFMT) e contou com a participação dos seguintes pesquisadores: João Carlos Barroso, Marinete Covezzi, Mário Cezar Silva Leite, Sueli Pereira Castro, Tereza Cristina Cardoso Higa e Verone Cristina da Silva. Em Mato Grosso do Sul foi coordenado por Idinaura Aparecida Marques (UFMS) com a participação dos pesquisadores Álvaro Banducci Jr. e Eudes Fernando Leite. Os grandes eixos temáticos, que estipulavam um eixo principal com subtemas, foram cinco: Produção Social do Espaço Pantaneiro e seu Entorno (eixo principal: Processos de reterritorialização, ocupação e produção social do espaço e seu entorno); Sócio-economia e Modos de Vida (eixo principal: Formas Históricas da Organização Social, Econômica e Política da Gente Pantaneira); Concepções e Relações da Gente Pantaneira com o Mundo Natural (eixo principal: Relações dos Seres Humanos com a Natureza e a Problemática da Conservação do Ambiente Pantaneiro e da Diversidade); Linguagens e Imaginários (eixo principal: Representações, Formas pelas quais homens e mulheres do Pantanal dão sentido ao mundo); Identidade Pantaneira: Uma Questão Cultural e Política (eixo principal: Identidades do ser pantaneiro). A pesquisa demonstrou uma modificação dessa tendência a partir da segunda metade dos anos 90 e nos anos iniciais de 2000. 
Neste artigo, terei como foco central, o imaginário dos homens e mulheres que habitam o espaço Pantanal, a percepção que desenvolvem do seu próprio espaço, a relação que estabelecem nele e com ele através dos mitos d'água, através de seus encantados. Aqui reinos são seres e seres são reinos e, de certo modo, tudo é água.

A população que vive no interior do Pantanal de Mato Grosso, boa parte às margens dos rios ou lagoas, desenvolve uma percepção do espaço que habita intimamente relacionada com a água. Os fluxos de cheia, de novembro a março, e de seca, de março a novembro interferem não apenas na inserção e no ritmo cotidiano da população naquele espaço, mas partilha também de suas elaborações mentais e imaginárias em relação ao mundo, à natureza, a vida e ao conjunto mítico que se engendra. E não se trata de determinismos geográficos, mas sim de uma espécie de co-autoria onde o espaço e a paisagem partilham do processo mental de sua própria elaboração. ${ }^{2}$

Os seres encantados d'água fazem parte da vida, dos medos, dos episódios, da memória, das paisagens e da cultura da região. O termo básico e recorrente que define toda a percepção e elaboração que se movimenta no interior do imaginário da população pantaneira na relação com os mitos e os espaços é o termo: encantado. Não há reinos no sentido tradicional do termo, ou no sentido em que se aplique talvez a boa parte dos contos de fada: reis, rainhas, princesas, príncipes encantados. Há mundos submersos, sobrenaturais que se misturam com o mundo natural, social e cultural. Ainda que os seres e os espaços sejam encantados, no Pantanal, o reino é o da natureza e o da cultura.

Claro que entender ou explicar conceitualmente o que este termo exprime não é problema para homens e mulheres do Pantanal, é problema para o pesquisador ao se defrontar com ele. Entender o significado do termo encantado demonstrou-se fundamental para o desenvolvimento de minha pesquisa ${ }^{3}$, pois ele é central e recorrente como percepção dos mitos e espaços do Pantanal. O termo encantado é utilizado como uma espécie de expressão "classificatória" ou mesmo um "conceito" pelas populações mais tradicionais e oralizadas da região do Pantanal. Ele determina não apenas lugares carregados de sobrenatural, mas também seres míticos como o Minhocão e o Negrinho d'água entre outros. Observei que a noção de encantamento que se elabora no imaginário popular pantaneiro, através das narrativas, engendra um universo onde alguns elementos convencionalmente distintos encontram-se enredados, entrelaçados e indistintos. Os reinos da natureza, da sobrenatureza e da cultura se misturam.

No plano mais amplo e globalizador do encantamento - que, na verdade, vai defini-lo no todo aparece, como trama fundamental, a indistinção entre natural e sobrenatural. Este imbricamento revela-se na medida em que natureza e sobrenatureza não se distinguem, muito menos se opõem, no interior da noção de encantamento. Nas vozes pantaneiras peixes, mitos d'água e a própria água intersecionam estes dois universos. As manifestações desses seres ou desses espaços são percebidas e narradas como encontros ou experiências com encantados. Isso significa dizer que para esta população a caracterização de determinados eventos como encantados é a sua explicação categórica e inquestionável, fechada em si mesma. Minha análise e interpretação revelou que nesta região encantado significa não exatamente, e só, o sobrenatural, mas a constituição de um universo indistinto entre natureza e sobrenatureza que passa diretamente pela humanização - e culturalização - de dados topográficos e dos seres imaginários. A noção de encantamento colocando natureza e sobrenatureza num mesmo plano e esfera desdobra-se e ramifica-se em uma série de outras indistinções - sem perder este assentamento básico - que provavelmente colocaria em pânico, ou desassossego, alguns pensamentos mais ortodoxos. A indistinção, natural-sobrenatural, do encantamento estende-se para uma não separação - não oposição - entre natureza e cultura. Para as águas do Pantanal como um todo, é a noção do encantamento da paisagem, do espaço e dos próprios mitos, que dissolve a ruptura natureza-cultura. Elementos que convencionalmente estariam separados e somente em uma das esferas - natureza ou cultura - aparecem imbricados, misturados e indiferenciados. E, mais, profundamente emaranhados com o sentido de sobrenatureza.

Nos vários relatos e narrativas, que recolhi durante a pesquisa de campo, a percepção do espaço, pela população, sempre se configurava como encantado. E na idéia de encantamento misturavam-se mitos das águas como a Mãe d'água, o Negrinho d'água, a serpente; seres naturais como peixes e jacarés; e a própria água como ser encantado independente. Trata-se, em verdade, de uma única noção de encantamento que abrange vários níveis aqui tratados mais ou menos como pontas ou manifestações diferenciadas: encantados como mitos d'água (negrinho d'água, serpente, mãe d'água) e a própria água como universo encantado.

A natureza de maneira geral é suscetível a concepções onde se conectam percepções práticas, utilitárias, cotidianas e percepções sobrenaturais e míticas. No imaginário popular brasileiro, quase sempre, a percepção da natureza elabora características antropomórficas para elementos naturais - certos

\footnotetext{
${ }^{2}$ Ver a esse respeito LEITE (2000) e LEITE (2003), especialmente o capítulo Impressão de Paisagens.

${ }^{3}$ Pesquisa de campo desenvolvida no Pantanal de Mato Grosso gravando as narrativas orais sobre os encantados d'água.
} 
vegetais "entristecem", outros "espirram", "assobiam”, "espalham sombras assustadoras", "gemem”, "gritam", são "agourentos" ou para produzir precisam ser abraçados por homem ou por mulher (CASCUDO, 1971, p. 55-83). O imaginário também elabora para a natureza poderes sobrenaturais e mágicos de atração, repulsão e até mesmo de sedução - plantas e ervas que neutralizam o "mau olhado", a inveja, o azar, atraem a boa fortuna, o dinheiro, o amor, a felicidade.Convém frisar que, via de regra, a antropomorfia e os poderes sobrenaturais não são dissociados. Em muitos casos, a humanização dos elementos naturais está na base para o encantamento e para o sobrenatural. Como se vê nos exemplos acima, são percepções da natureza fortemente simbólicas e mágicas que se estendem desde os efeitos terapêuticos das ervas, acompanhados de práticas mágicas (CASCUDO, 1971, p. 55-83), até as atribuições de racionalidade à natureza. Em alguns casos, a noção de natureza incorpora a noção de Deus ou vice-versa (SILVA, 1989, p. 21).

A água, como elemento de misturas por excelência, recebe sempre uma carga mágico-simbólica muito variada que vai desde sua feminização e sua ferocidade ${ }^{4}$, até elaborações mais complexas. Em sua violência "assume uma cólera específica, ou seja, a água recebe facilmente as características de um tipo de cólera” (BACHELARD, 1989, p.16).

Para a água do Pantanal e para algumas baias, a baía de Chacororé por exemplo, o encantamento revela várias realizações desta carga sobrenatural-simbólica no imaginário popular pantaneiro sempre muito ligada a este tipo de cólera.

As populações ribeirinhas ou caiçaras, de maneira geral, desenvolvem uma percepção "do meio" e de "seus fenômenos naturais" onde: "De um lado, há um vasto conhecimento empírico adquirido pela observação continuada dos fenômenos físicos e biológicos". [...] De outro lado as explicações para tais fenômenos passam pela representação simbólica e pelo imaginário" (DIEGUES, 1995, p. 5-6).

Alguns estudos da Antropologia e Etnologia já demonstraram que é mais ou menos comum para as populações caiçaras a percepção em relação às águas que elabora a noção de um mundo reproduzido do mundo do seco. Ou seja, o universo submerso é uma reprodução do universo de fora d'água. Tudo o que se tem no seco se tem na água (SILVA, 1989, p. 84). Esta idéia-imagem, este imaginário, chega a grandes requintes de elaboração quando os próprios peixes são entendidos numa complexidade equivalente à humana e social. Têm casas, famílias, saem para trabalhar, voltam para o almoço etc.(LIMA, apud SILVA, 1989, p. 39). Mas, até onde pude observar, não se estabelece claramente, nestes casos, a idéia de que isto decorra de uma sobrenatureza das águas. Trata-se, se assim se pode dizer, de uma "simples" reprodução.

Para a população pantaneira, de forma abrangente esta concepção de mundo aquático reproduzido não é estranha ou desconhecida. Mas o imaginário popular pantaneiro introduz um outro elemento que faz com que o universo reproduzido ganhe outra dimensão: a do sobrenatural e do encantamento. Desta forma, estabelece-se que se trata somente até certo ponto de uma reprodução. De certo modo, uma reprodução que muda a ontologia essencial da imagem ou do mundo fornecido como modelo. Uma reprodução que engendra uma outra ordem diferente da "original", do mundo do seco.

Para Bachelard, comentando as metáforas da água violenta e que reage às provocações humanas, "os nervos da água estão à flor da pele". E há algumas "águas que têm a epiderme sensível" (BACHELARD, 1989, p. 190-191). Observa ainda Bachelard que "alguns lagos são particularmente excitáveis; reagem imediatamente a menor provocação" (BACHELARD, 1989, p. 188). A baía de Chacororé, a maior do Pantanal mato-grossense e objeto central de minhas pesquisas, reage os barulhos humanos, conversas, gritos ou mesmo assobios. São eles que funcionam como provocação e a baía reage violentamente levantando suas ondas. Para a maioria da população desta região do Pantanal a baía de Chacororé é encantada. Na voz-memória e no imaginário popular inscreve-se a idéia de que ela possui poderes sobrenaturais e as ondas que provoca são uma das formas de manifestação destes poderes.

Nos vários relatos, que recolhi durante a pesquisa de campo, a percepção daquele espaço, pela população, sempre se configurava como encantado. E na idéia de encantamento misturavam-se mitos das águas como a Mãe d'água, o Negrinho d'água, a serpente; seres naturais como peixes e jacarés; e a própria baía de Chacororé como ser encantado independente.

Num primeiro plano, um dos fortes elementos de caracterização do encantamento de Chacororé são as grandes ondas que ela provoca. Todas as suas manifestações sobrenaturais estão intimamente ligadas às ondas. Ocorre aqui, nesta primeira instância, uma conexão entre o que se pode chamar de natural e sobrenatural que vai se espalhar para a percepção do encantamento - e mesmo defini-lo- como um todo para as águas de Chacororé e de algum modo para as águas do Pantanal. Esta manifestação de

\footnotetext{
${ }^{4}$ Note-se também que para Bachelard a “água má” muda de sexo “torna-se masculina”. Cf. também DURAND (1989).
} 
ebulição das águas como reação a barulhos ou manifestação de seres sobrenaturais não é exclusividade da baía de Chacororé pode ocorrer em todas as outras baias ou em todos os rios do Pantanal.

Estas ondas que poderiam ser atribuídas a fatores hidrológicos e climáticos - devido ao conhecimento, à familiaridade, aos aspectos práticos e cotidianos da relação da população com estas águas - são atribuídas ao sobrenatural ${ }^{5}$ e ao encantamento. E assim se abre um amplo leque de realizações fabulosas. Dá-se, deste modo, uma inextrincável simbiose entre Chacororé e os seres imaginários. Como se verá a seguir, nos fragmentos-exemplos, desde a sutil humanização da baía até os mitos d'água, as ondas permeiam todas as manifestações de encantamento de Chacororé.

Ouçam-se algumas vozes do Pantanal:

Era umas dez horas da noite já. Levantava as ondas, ficava as ondas bravas, a baía brava quase que derrubou nós da canoa. [...] falavam que era encantada. Ela embrabeceu, ficou brava. Eu não sei o que aconteceu, sei que sempre ela fica. Forma onda grande mesmo que o senhor não passa, eu não passo. Fica brava. [...] Sempre vejo falar que a baía é encantada. Meu pai dizia que é encantada. ${ }^{6}$

Eu vinha da beira do rio com meu pai. Aí, nós vínhamos remando. Aí, entramos na baía. A baía estava lisinha, não tinha uma onda. Aí, nós vimos..., no meio da baía, tinha uma praia, uma ilha, tinha um tipo de uma menininha, não sei se era guri ou se era menina, brincando com a areia. Punha areia pra cá, areia pra lá. Aí, pressentiu nós, correu e caiu na água. Dessa hora pra cá a onda cresceu que não fomos capazes de passar na baía. ${ }^{7}$

A braveza da baía de Chacororé manifestada pelas ondas é a "marca registrada" de seu encantamento. E neste sentido, por outro lado, o encanto de Chacororé insere-se numa poética mais geral e de todas as águas.

Ainda que, para efeitos didáticos, se possa aqui entender e analisar o encantamento nestas ramificações ou instâncias - mitos d'água, seres naturais e Chacororé encantada individualmente - devo esclarecer que elas compõem um todo indissociável. Trata-se, em verdade, de uma única noção de encantamento que abrange vários níveis.

Um segundo plano, ou instância, do encantamento - absolutamente conectado ao primeiro, visto acima $^{8}$ - é a noção de Chacororé como ser mítico ou sobrenatural individualizado e matricial. Isto se manifesta quando a maioria das narrativas refere-se a ela como detentora do poder para engendrar os outros seres. Ela é - assim como em alguns casos a água de maneira geral - um reino em si. Além das ondas e da braveza, atribui-se à baía a realização, "a apresentação", dos outros seres encantados. A idéia é a de que tudo de sobrenatural que se manifesta na Chacororé é criação dela e pelo seu próprio desejo. Dentro desta percepção os mitos d'água, mais gerais - como a Mãe d'água o Negrinho d'água ou mesmo o Cavalo e o Boi d'água - deixam de ser, até certo ponto, individuais e de todas as águas, com "vida própria", e passam a ser realização, "apresentação", da baía.

Ouçam-se, mais uma vez, as vozes do Pantanal:

Olha, na, nessa baía tem. Nessa tem porque ela é encantada. [...] Chacororé ali é encantado que é uma coisa! O encanto da baía representa de tudo quanto é movimento que você está enxergando. Lá, ele (o encanto) representa um homem, uma mulher, andando.

Mas é a baía que faz, é a baía. Tudo é a baía! A apresentação é dela. De gente também. Dessas coisas que ela faz. ${ }^{9}$

Veja-se que neste caso a baía de Chacororé é concebida como um universo-sobrenatural-mãe destes seres. De determinada maneira, eles, os seres imaginários, não têm "existência" própria. São a manifestação e "apresentação" de seu encanto. "Tudo é a baía!"

A elaboração essencial que se tem aqui é que estes seres - sejam eles quais forem - não "moram" ou "residem" na baía, mas são a própria baía e suas águas. Eles não habitam aquele espaço, eles são o próprio espaço. Misturados e integrados à Chacororé. Só tomam formas específicas e se manifestam

\footnotetext{
${ }^{5}$ Preciso esclarecer que a população pantaneira não explicita ou elabora a noção de sobrenatural. Isto é, não se utiliza desta expressão ou nomenclatura. A expressão utilizada é sempre "encantado" ou "encanto", a idéia de sobrenatural manifesta-se quando acrescenta-se a afirmação de que se tratam de "coisas do outro mundo".

${ }^{6}$ Seu Arnaldo, Arnaldo ferreira Leite, mimoseano (de Mimoso), alfabetizado. Nossa conversa foi gravada em Porto São Bento. Respeitei em todas as transcrições as repetições, a sintaxe, e os regionalismos dos narradores. Apenas grafei as palavras dentro da ortografia padrão da língua portuguesa. O relato de seu Arnaldo é sobre o encanto, ligado às ondas, de Chacororé. Para maiores detalhes e relatos completos ver minha tese de doutorado "Águas Encantadas de Chacororé: Paisagens e Mitos do Pantanal" (LEITE, 2000) e meu livro (LEITE, 2003).

${ }^{7}$ Dona Xanô, Adiles Teixeira Leite, mimoseana, alfabetizada. Dona Xanô é esposa de seu Arnaldo e gravei nossa conversa no mesmo local. O relato dela, como se vê acima, é sobre um ser, menino ou menina encantado, da baía.

${ }^{8}$ É preciso esclarecer que estou fazendo uma divisão, em planos e instâncias, apenas para fins mais "didáticos" e que, em verdade, trata-se, no todo, da noção de encantamento da baía de Chacororé e das águas do Pantanal. São várias realizações do mesmo encantamento, e aqui se incluem os mitos d'água.

${ }^{9}$ Seu Donato. Donato Rodrigues de Souza, mimoseano. Gravei nossa conversa em Cuiabá.
} 
quando, e como, ela quiser. Assim como as ondas, é ela, e suas águas, que os engendra. E mais: ao engendrar os seres imaginários e os mitos, numa espécie de movimento e dilatação do encantamento, a baía de Chacororé funde-se com eles tornando-se um único ser. Ou seja, trata-se de um processo de criação-fusão entre seres, em tese, diferentes: um, o criador, a baía de Chacororé; outro, a criatura, os mitos e seres imaginários. Mas, neste caso, a criatura engendrada mistura-se ao criador na sua totalidade. No limite, todos os mitos d'água quando se manifestam na baía - e como realização dela - tornam-se a própria Chacororé.

O inextrincável imbricamento entre as águas de Chacororé e os mitos pode ser verificado brevemente aqui com um outro exemplo: o Barco Fantasma. O Barco Fantasma é uma das realizações sobrenaturais mais conhecidas de Chacororé. As narrativas dizem que era uma "bandeira do Divino" esmolando que lá afundou, provavelmente no final do século XIX, e que todos os que estavam na barca morreram afogados. A festa, ou a bandeira, do Divino Espírito Santo envolve, em uma de suas partes, a esmola com um grupo de fiéis perambulando, por um tempo, com a bandeira e uma banda de música recolhendo donativos para a festa. Normalmente, a banda toca o Hino do Senhor Divino ${ }^{10}$. Conta-se que a barca do Divino atravessava a baía de Chacororé à noite para esmolar, às vezes em Mimoso, comunidade às margens da baia, às vezes em Acorizal, às margens do rio Cuiabá, e ia em festa. Com a bandeira vermelha à frente e a banda tocando o hino.

Recuperando-se a idéia de que a baía, ou a água em geral, não gosta de barulho, este barco, apesar de ser a bandeira do Divino, já estava fadado a enfrentar a braveza das águas. E foi o que aconteceu. De uma hora para outra, de repente, formaram-se as ondas que viraram o barco e afogaram todos. E esse barco encantou-se. De tempos em tempos ele retorna à superfície com a bandeira no mastro, os afogados e o som da banda. Ele surge das águas. ${ }^{11}$ A bandeira, em verdade, foi vítima do encantamento e ao sucumbir, ao naufragar, tornou-se também encantada. Mas aqui é preciso ressaltar que ela incorporou-se às águas encantadas de Chacororé. Um dos poderes dos encantados é encantar, tornar igual, aqueles que pegam. ${ }^{12}$ Veja-se, no fragmento a seguir, de que forma o barco da bandeira do Divino se funde com a baía:

Aconteceu comigo. Quando essa baía ondava mesmo, que tinha água pra ondar. O senhor pra passar nesta baía, a coisa mais fácil que tinha pra cortar a onda: o senhor tirava um níquel de dinheiro e jogava lá e tchiiii, alisava na hora. Acalmava na hora! Pois é, então, estava pagando ali. Porque ali afundou a bandeira, né? Estava dando uma esmola ali. Jogava a moeda cessavam as ondas! ${ }^{13}$

Note-se que a esmola, o "níquel de dinheiro", jogado nas águas, tem o poder de acalmar as águas. Acabar com suas ondas e permitir que o navegador a atravesse com tranqüilidade. Entretanto, em tese, a nau do Divino Espírito Santo não tem nada a ver com a formação das ondas ou a braveza da baía, além do fato de, possivelmente, ter sido uma de suas vítimas. Mas, como se viu, ocorre uma fusão Chacororé-barco que faz com que ao se pagar a esmola para a bandeira as ondas encantadas desapareçam. Portanto, nesta configuração Chacororé e bandeira são, por assim dizer, um único ser.

Esta noção de ser mítico-matricial, que chamei aqui de segundo plano do encantamento, desdobra-se e complexifica-se numa terceira instância que, em verdade, abrange e sintetiza a elaboração do encantamento das águas como um todo. Que é a já apontada idéia da reprodução do mundo do seco.

O mundo das águas é uma reprodução do mundo seco, mas não se trata de uma simples reprodução natural. Todos os seres e coisas reproduzidos ao serem aquaticamente "duplicados" mudam de categoria: sobrenaturalizam-se. Sem, entretanto, perder o seu caráter natural.

E é neste imbricamento, nesta indistinção entre natural e sobrenatural, que se tece a noção de encantamento. O reino encantado aqui é o reino das águas.

Note-se como os "reinos" se conectam e se cruzam. Um dito popular, muito comum na região e que denota bem e de imediato esta idéia, quando se refere à água é a seguinte: "na água tem mais ser vivente do que cabelo na terra!"

A princípio poder-se-ia pensar que esta expressão refere-se à existência de varias formas de vida natural nas águas, peixes, jacarés, cobras etc. Mas a bióloga Carolina da Silva e a antropóloga Joana Fernandes detectaram um campo semântico para esta expressão um pouco mais complexo e profundo, dizem elas:

Apesar de toda a técnica, estratégias, cuidados, ciclos lunares e nível da água que os pescadores devem observar, parece existir algo muito mais importante que regulamenta a pescaria.[...] Isto

\footnotetext{
${ }^{10}$ Cf. CASCUDO (sd, p. 356-357) e CASCUDO (1984, p. 367-417).

${ }^{11}$ Ver a este respeito, incluindo as narrativas, minha tese de doutorado. Especificamente, o capítulo 3.5. Chacororé: A Nau Fantasma do Divino Espírito Santo (LEITE, 2000, p. 118-123). Em versão um pouco modificada, meu livro: LEITE, 2003, p. 111-116.

${ }^{12} \mathrm{O}$ Negrinho d'água é um dos encantados que tem este poder: transformar suas vítimas em outros negrinhos d'água.

${ }^{13}$ Seu Miguel, Manuel Miguel Araújo, melgassense, alfabetizado. Gravei nossa conversa em Estirão Comprido.
} 
quer dizer que as águas são habitadas por muitas espécies de seres, além dos peixes, e todos perigosos aos humanos.(SILVA e SILVA, 1995, p. 165).

Nas narrativas que recolhi, defrontei-me muito recorrentemente com seres como o Cavalo d'água, o Boi d'água, a serpente, o Negrinho d'água e a Mãe d'água qualificados e tratados por encantados, ou por seu sinônimo mais comum: bicho d'água. Observei que esta expressão aplica-se, em geral, para todos os seres imaginários das águas e para a própria água.

Sobre uma gigantesca serpente, por exemplo, seu Donato dizia-me: Ela é bicho como jacaré. Note-se que ser bicho como jacaré remete-se ao reino da natureza. E eu insistia: Mas então é coisa deste mundo seu Donato? E antes dele, era sua esposa, Dona Maria, que me respondia: Não, é do outro mundo. O senhor nunca viu coisa do outro mundo? Note-se que aqui outro mundo é nitidamente o mundo sobrenatural. E seu Donato, na seqüência, para minha surpresa concluía: É de outro mundo, porque os, os bichos de, de, rio, é, é da água. No seco ele não pega! É encantado! E vale dizer que esta serpente ao mesmo tempo em que levanta a canoa de seu Donato nas costas, mais de dois metros acima da água, tem a cabeça presa no altar da igreja de Nossa Senhora das Dores na cidade de Barão de Melgaço, distante muitos quilômetros. Deste modo, percebe-se visivelmente as duas pontas, ou os dois pólos, com que ela se conecta: de um lado, a materialidade, o "bicho como jacaré", o ser encarnado fisicamente, o mundo natural; por outro, todas as grandes imagens-serpentes míticas, do outro mundo, do reino do sobrenatural. A materialidade desta serpente é manifesta quando a canoa de seu Donato é levantada por ela. Recolhi também alguns relatos que narram que o pescador atirou o arpão no "bicho d'água", no encantado, acertando-o. Explicitamente, o arpão fincou-se no corpo do bicho d'água que ficou "zoando", nadando pra lá e pra cá, no rio. O sobrenatural, neste caso, é garantido pelo fato do bicho d'água ter descoberto quem o atingiu e "metido o bico", batido, no barranco até derrubar a casa do pescador. Note-se também que a conclusão de seu Donato é que se trata de "coisa do outro mundo" "porque é da água", de rio, mas é encantado (LEITE, 2003, p. 136-137).

Neste mesmo aspecto se pode falar também sobre o Negrinho d'água que é encantado, mas pode dar enormes surras nos pescadores que pega e leva para sua casa em baixo d'água. (LEITE, 2003, p. $137)^{14}$.

Mesmo quando se trata do Cavalo e do Boi marinho há a noção clara de que eles não são apenas reprodução ou versão aquática de seus equivalentes naturais da terra. Eles são encantados. Encantados, mas podem sair da água no fim do dia ou à noite para se alimentar de capim, para pastar (FERNANDES, 1998, p. 113-114).

Uma radicalização desta concepção aparece em narrativas que apontam os mitos como seres dotados de racionalidade e com curiosidade com relação aos humanos. São alçados a uma condição de quase cientistas. Veja-se o exemplo:

Eles também deve ter curiosidade sobre nós que vivemos aqui na terra, entendeu? Pode pegar pra levar pra pesquisar. Porque a gente não sabe a ciência deles, o que eles pensam também, né? Mas que existe, existe! ${ }^{15}$

Porque eles tem cidade deles (os encantados). E os homens que é macho pega as meninas, leva pra cidade deles. O que, as mulheres que pega os homens também, leva pra cidade deles. Debaixo d'água. Em baixo da água! Tem cidade deles! O senhor vê que hoje todas as coisas estão dependendo de, de, muito estudo pra saber certas coisas. Os jacarés têm cidade, dourado tem cidade. Tudo quanto é esses peixes grandes tem cidade deles. Todos têm cidade! ${ }^{16}$

Veja-se que no primeiro relato acima configura-se explicitamente a idéia de que os encantados não só têm curiosidade sobre "nós que vivemos aqui na terra" como a de que têm uma ciência. E embora não sendo explícito, o segundo relato refere-se ao fato de que "hoje todas as coisas estão dependendo" de "muito estudo pra saber certas coisas". De certo modo, a afirmação "muito estudo", do segundo fragmento, não está completamente fora do campo semântico de "curiosidade sobre nós que vivemos aqui na terra" e "a ciência deles", do primeiro. Não obstante serem narradores diferentes, o segundo relato traz a questão completamente inserida no contexto tanto da existência de cidades dos encantados quanto de cidades dos seres naturais. Este relato faz inclusive uma distinção sexual na preferência, dos encantados, de escolha das vítimas. É preciso notar também que, neste caso, permeia a fala dos narradores a racionalidade atribuída aos encantados e seres naturais.

\footnotetext{
${ }^{14}$ Narrativa de Seu Manoel Miguel Araújo.

${ }^{15}$ Narrativa de Dirce Padilha (FERNANDES, 1988, p. 61).

${ }^{16}$ Relato de Seu Donato. Note-se que o narrador começa falando dos encantados e termina falando dos seres naturais. A idéia aqui é que tanto os encantados quanto peixes e jacarés possuem cidades em baixo d'água. E mais uma vez percebe-se que são colocados e tratados no mesmo plano, sem distinção. Deste modo, a tradicional distinção entre Natureza e Cultura se dilui bastante uma vez que a própria natureza se reveste de características culturais (LEITE, 2003, p. 152).
} 
$\mathrm{Na}$ verdade toda a ampliação do encantamento onde se equacionam natureza-cultura e sobrenatureza está ligada diretamente à noção da água como um outro mundo. Essa idéia apresentarepresenta o mundo subaquático como reprodução do mundo do seco. O mundo submerso é reprodução do mundo do seco, do mundo da terra. Daí que não é raro encontrar o Boi d'água, o Cavalo d'água, boiadas inteiras e seus boiadeiros surgindo das águas. Mas há a percepção clara de que não se tratam de simples reprodução, todos eles são encantados. O que se distingue no imaginário popular pantaneiro do imaginário de outras comunidades à beira d'água que também elaboram essa concepção, de mundo aquático reproduzido, é que para o Pantanal esta reprodução aquática muda ontologicamente os seres. A reprodução aquática do mundo sobrenaturaliza e encanta o universo submerso. A água é o outro mundo. Sem deixar de ser, ao mesmo tempo, o próprio universo natural.

Assim a mitopoética pantaneira - nas vozes, na memória, nas narrativas, no revivido do contar e recontar - revela o encanto das águas constituído na indistinção dos mundos. Estas narrativas redesenham e reorganizam um outro Pantanal. E seu mundo e seus reinos nos atravessam! Para a população pantaneira não se trata de encantados, reinos, natureza, sobrenatureza, cultura, trata-se de labuta diária, risos, medos, amores, tristezas, alegrias. Os narradores e narradoras deste trabalho, desta pesquisa, cartografam reinosexistências, pantanais-vidas fissurando, rompendo, atravessando todo e qualquer ponto final.

\section{BIBLIOGRAFIA}

BACHELARD, Gaston. A água e os sonhos: ensaio sobre a imaginação da matéria. Trad. Antonio de Pádua Danesi. São Paulo: Martins Fontes, 1996.

CASCUDO, Luis da Camara. Tradição, ciência do povo: pesquisas de cultura popular no Brasil. São Paulo: Perspectiva, 1971.

CASCUDO, Luis da Camara. Literatura oral no Brasil. 3.ed. Belo Horizonte; São Paulo: Itatiaia; Edusp, 1984.

CASCUDO, Luis da Camara. Dicionário do folclore brasileiro. Rio de Janeiro: s.d.

DIEGUES, Antonio Carlos. Povos e mares: leituras em socioantropologia marítima. São Paulo: NUPAUB-USP, 1995.

DURAND, Gilbert. As estruturas antropológicas do imaginário. Trad. Hélder Godinho. Lisboa: Presença, 1989.

FERNANDES, Frederico Augusto Garcia. Entre histórias e tererés: o ouvir da literatura pantaneira. Dissertação de Mestrado. Faculdade de Ciências e Letras da Unesp, Assis-SP, 1998.

LEITE, Mário Cezar Silva. Águas encantadas de Chacororé: paisagens e mitos do Pantanal.. Tese (Doutorado em Comunicação e Semiótica) - Programa de Estudos Pós-graduados em Comunicação e Semiótica, Pontifícia Universidade Católica de São Paulo. São Paulo, 2000.

LEITE, Mário Cezar Silva. Águas encantadas de Chacororé: natureza, cultura, paisagens e mitos do Pantanal. Cuiabá: Cathedral-Unicen Publicações, 2003.

SILVA, Carolina Joana da; SILVA, Joana Aparecida Fernandes. No ritmo das águas do Pantanal. São Paulo: NUPAUB-USP; Cuiabá: Ed. UFMT, 1995.

SILVA, Gláucia Oliveira da. Tudo que tem na terra tem no mar: a classificação dos seres vivos entre os trabalhadores da pesca em Piratininga, Rio de Janeiro. Rio de Janeiro: FUNARTE, Instituto Nacional do Folclore, 1989. 